\title{
LX. On the potential of an ellipsoid at an external point
}

\author{
Colonel A.R. Clarke C.B. F.R.S.
}

To cite this article: Colonel A.R. Clarke C.B. F.R.S. (1877) LX. On the potential of an ellipsoid at an external point, Philosophical Magazine Series 5, 4:27, 458-461, DOI: 10.1080/14786447708639369

To link to this article: http://dx.doi.org/10.1080/14786447708639369

曲 Published online: 13 May 2009.

Submit your article to this journal $\sqsubset \pi$

Џ Article views: 2

Q View related articles $\sqsubset$ 
ence is collected on $\mathrm{C}_{2}$ when $\mathrm{C}_{1}$ is charged up to a certain potential-level, and that which in the charging of $\mathrm{C}_{2}$ up to the same potential is through influence collected on $\mathrm{C}_{1}$, are equal the one to the other.

Beside these two conclusions, here cited as examples, referable to two very simple special cases, from equation (I.) many other similar inferences can of course be drawn.

LX. On the Potential of an Ellipsoid at an External Point. By Colonel A. R. ClaRKE, C.B., F.R.S.*

TN connexion with the subject of the attraction of the earth 1 upon external objects, there is a series which is usually brought forward by writers on astronomy, viz. that which results from expanding into a series in descending powers of $r$ the expression for $V$,

$$
\mathrm{V}=\iiint \frac{d x d y d z}{\left\{(f-x)^{2}+(g-y)^{2}+(h-z)^{2}\right\}^{\frac{1}{3}}},
$$

r being the distance $=\left(f^{2}+g^{2}+h^{2}\right)^{\frac{1}{2}}$ of the attracted external particle from the origin, $x, y, z$ the coordinates of any element of the mass, the density being unity throughout. Put $x^{2}+y^{2}+z^{2}=\rho^{2}, \alpha x+\beta y+\gamma z=\sigma$, where $\alpha, \beta, \gamma$ are the direction-cosines of $r$; then the radical in the expression for $V$ may be expanded in the form

$$
\frac{1}{r}+\frac{Q_{1}}{r^{2}}+\frac{Q_{2}}{r^{3}}+\frac{Q_{3}}{r^{4}}+\ldots,
$$

where $Q_{i}$ is a homogeneous function of $x, y, z$ of the degree $i$. When the body is an ellipsoid referred to its principal axes, the terms in which $i$ is odd will disappear in integrating over the volume of the ellipsoid; so that in this case, $\mathbf{M}$ being the mass of the ellipsoid,

$$
\mathrm{V}=\frac{\mathrm{M}}{r}+\frac{1}{r^{3}} \int \mathrm{Q}_{2} d m+\frac{1}{r^{5}} \int \mathrm{Q}_{4} d m+\frac{1}{r^{7}} \int \mathrm{Q}_{6} d m+\ldots,
$$

which is the series alluded to. Lagrange's investigation of the terms (as far as just written down) of this series is referred to in Todhunter's 'History of the Theory of Attraction and the Figure of the Earth,' vol. ii. p. 161. See also Thomson and Tait, 'Natural Philosophy,' pp. 401, 402 ; Pontécoulant, Theorie Analytique du Systeme du Monde, ii. p. 233, where the above expression for the potential is given as one suitable

* Communicated by the Author. 
only when $r$, as compared with the dimensions of the attracting body, is very large -as, for instance, in the investigation of the disturbance of the moon's motion produced by the nonsphericity of the earth, and of the reaction of the same disturbing force on the earth, causing lunar nutation and precession. But the fact is, that the first two terms of the series are sufficient for any external point, however near, provided the square of the earth's ellipticity be neglected; for the ratio of the successive terms is not of the order $\frac{a^{2}}{r^{2}}$, but $\frac{a^{2}-b^{2}}{r^{2}}, a, b$ being the semidiameters of the earth.

If $\mathrm{P}_{n}$ be Legendre's coefficient of the order $n$, then we have, $\mu$ being the cosine of the angle between $r$ and $\rho$,

$$
\left(r^{2}-2 r \rho \mu+\rho^{2}\right)^{-t}=\frac{P_{0}}{r}+\frac{P_{1} \rho}{r^{2}}+\frac{P_{2} \rho^{2}}{r^{3}}+\frac{P_{3} \rho^{3}}{r^{4}}+\ldots ;
$$

consequently

$$
\int Q_{i} d m=\int P_{i} \rho^{i} d m \text {. }
$$

Now we require only the even coefficients; and their values (Todhunter's 'Functions of Laplace, Lamé, and Bessel,' p. 4)

are :-

$$
\begin{aligned}
& \mathrm{P}_{2}=\frac{3}{2} \mu^{2}-\frac{1}{2} \\
& \mathrm{P}_{4}=\frac{5.7}{2.4} \mu^{4}-\frac{3.5}{2.4} 2 \mu^{2}+\frac{1.3}{2.4}, \\
& \mathrm{P}_{6}=\frac{7.9 .11}{2.4 .6} \mu^{6}-\frac{5.7 .9}{2.4 .6} 3 \mu^{4}+\frac{3.5 .7}{2.4 .6} 3 \mu^{2}-\frac{1.3 .5}{2.4 .6} ;
\end{aligned}
$$

whence the values of $Q$, since $\rho \mu=\sigma$, are

$$
\begin{aligned}
& \mathrm{Q}_{2}=\frac{3}{2} \sigma^{2}-\frac{1}{2} \rho^{2}, \\
& \mathrm{Q}_{4}=\frac{5.7}{2.4} \sigma^{4}-\frac{3.5}{2.4} 2 \sigma^{2} \rho^{2}+\frac{1.3}{2.4} \rho^{4}, \\
& \mathrm{Q}_{6}=\frac{7.9 .11}{2.4 .6} \sigma^{6}-\frac{5.7 .9}{2.4 .6} 3 \sigma^{4} \rho^{2}+\frac{3.5 .7}{2.4 .6} 3 \sigma^{2} \rho^{4}-\frac{1.3 .5}{2.4 .6} \rho^{6} .
\end{aligned}
$$

For the integration of $Q_{2}$ we have

$$
\int x^{2} d m=\frac{\mathrm{M}}{5} a^{2}: \int y^{2} d m=\frac{\mathrm{M}}{5} b^{2}: \int z^{2} d m=\frac{\mathrm{M}}{5} c^{2} ;
$$

and there is no difficulty in arriving at the equation

$$
\int \mathrm{Q}_{2} d m=-\frac{\mathrm{M}}{15}\left\{\mathrm{P}_{2}^{\prime}\left(e_{2}^{2}-e_{3}^{2}\right)+\mathrm{P}_{2}^{\prime \prime}\left(e_{3}^{2}-e_{1}^{2}\right)+\mathrm{P}_{2}{ }^{\prime \prime}\left(e_{1}^{2}-e_{2}^{2}\right)\right\} \text {, }
$$


where $e_{2}^{2}=b^{2}-c^{2} ; e_{2}^{2}=c^{2}-a^{2} ; e_{3}^{2}=a^{2}-l^{2}$; and $\mathrm{P}_{2}{ }^{\prime}, \mathrm{P}_{2}{ }^{\prime \prime}, \mathrm{P}_{2}{ }^{\prime \prime \prime}$ are what $\mathrm{P}_{2}$ becomes when $\alpha, \beta, \gamma$ are respectively written for $\mu$.

We may write the next term thus,

$$
\mathrm{Q}_{4}=\mathrm{A} x^{4}+\mathrm{B} y^{4}+\mathrm{C} z^{4}+\mathrm{A}^{\prime} x^{2} y^{2}+\mathrm{B}^{\prime} y^{2} z^{2}+\mathrm{C}^{\prime} z^{2} x^{2}+\mathrm{W},
$$

where $\mathrm{W}$ includes all terms in which the exponents are odd, which disappear in integration. But $Q_{i}$ must satisfy the differential equation

$$
\frac{d^{2} Q_{i}}{d x^{2}}+\frac{d^{2} Q_{i}}{d y^{2}}+\frac{d^{2} Q_{i}}{d z^{2}}=0 . \quad \text {. . . . . }
$$

Applying this to $Q_{4}$, and remembering that the equation is identically true, we get these equations:-

whence

$$
\begin{aligned}
& 6 \mathrm{~A}+\mathrm{A}^{\prime}+\mathrm{C}^{\prime}=0, \\
& 6 \mathrm{~B}+\mathrm{A}^{\prime}+\mathrm{B}^{\prime}=0, \\
& 6 \mathrm{C}+\mathrm{B}^{\prime}+\mathrm{C}^{\prime}=0,
\end{aligned}
$$

$$
\begin{aligned}
& A^{\prime}+3(A+B-C)=0, \\
& B^{\prime}+3(-A+B+C)=0, \\
& C^{\prime}+3(A-B+C)=0 .
\end{aligned}
$$

On integrating the expression for $Q_{4}$, after substituting these values of $\mathrm{A}^{\prime}, \mathrm{B}^{\prime}, \mathrm{C}^{\prime}$, it is to be observed that

$$
\int x^{4} d m=\frac{1.3}{5.7} \mathrm{M} a^{4} ; \int x^{2} y^{2} d m=\frac{1}{5.7} \mathrm{M} a^{2} b^{2},
$$

with corresponding values for the other integrals. Also $\mathrm{A}, \mathrm{B}, \mathrm{C}$ are equal respectively to $\mathrm{P}_{4}^{\prime}, \mathrm{P}_{4}^{\prime \prime}, \mathrm{P}_{4}^{\prime \prime \prime}$, where the accents have the meaning already explained. Thus we get

$$
\int \mathrm{Q}_{4} d m=-\stackrel{3 \mathrm{M}_{1}}{5.7}\left\{\mathrm{P}_{4}^{\prime} e_{3}^{2} e_{2}^{2}+\mathrm{P}_{4}^{\prime \prime} e_{1}^{2} e_{3}^{2}+\mathrm{P}_{4}^{\prime \prime \prime} e_{2}^{2} e_{1}^{2}\right\} \ldots
$$

For the next term put $\mathrm{Q}_{6}=\mathrm{I}_{1} \sigma^{6}+\mathrm{I}_{2} \sigma^{4} \rho^{2}+\mathrm{I}_{3} \sigma^{2} \rho^{4}+\mathrm{I}_{4} \rho^{6}$; and then, expanding, we get

$$
\begin{aligned}
\mathrm{Q}_{6}=\mathrm{A} x^{6}+\mathrm{B} y^{6}+\mathrm{C}^{6}+\mathrm{A}_{1} x^{2} y^{4}+\mathrm{A}_{2} x^{4} y^{2}+\mathrm{B}_{1} y^{2} z^{4}+\mathrm{B}_{2} y^{4} z^{2} \\
+\mathrm{C}_{1} z^{2} x^{4}+\mathrm{C}_{2} z^{4} x^{2}+\mathrm{E} x^{2} y^{2} z^{2}
\end{aligned}
$$

plus terms involving odd powers of $x, y, z$, which disappear in integration. On substituting $Q_{6}$ in the differential equation (3), which it has to satisfy, the following relations are found amongst the coefficients with which we are concerned :-

$$
\begin{array}{ll}
15 \mathrm{~A}+\mathrm{A}_{2}+\mathrm{C}_{1}=0, & 6 \mathrm{~A}_{1}+6 \mathrm{~A}_{2}+\mathrm{E}=0, \\
15 \mathrm{~B}+\mathrm{A}_{1}+\mathrm{B}_{2}=0, & 6 \mathrm{~B}_{1}+6 \mathrm{~B}_{2}+\mathrm{E}=0, \\
15 \mathrm{C}+\mathrm{C}_{2}+\mathrm{B}_{1}=0, & 6 \mathrm{C}_{1}+6 \mathrm{C}_{2}+\mathrm{E}=0 .
\end{array}
$$


We cannot from these six equations express $A_{1}, A_{2}, B_{1}, B_{2}$, $\mathrm{C}_{1}, \mathrm{C}_{2}$ in terms of the other four coefficients, because on comparing the sums of the two sets of equations we get $\mathrm{E}=30(\mathrm{~A}+\mathrm{B}+\mathrm{C})$; therefore we must seek some simple relation amongst the coefficients that may be used as another equation. The coefficients are

$$
\begin{aligned}
& A=I_{1} \alpha^{6}+I_{2} \alpha^{4}+I_{3} \alpha^{2}+I_{4}, \\
& A_{1}=15 I_{1} \alpha^{2} \beta^{4}+I_{2}\left(6 \alpha^{2} \beta^{2}+\beta^{4}\right)+I_{3}\left(\alpha^{2}+2 \beta^{2}\right)+3 I_{4}, \\
& A_{2}=15 I_{1} \alpha^{4} \beta^{2}+I_{2}\left(6 \alpha^{2} \beta^{2}+\alpha^{4}\right)+I_{3}\left(2 \alpha^{2}+\beta^{2}\right)+3 I_{4},
\end{aligned}
$$

from which the others may be written down. The simplest relation that suggests itself arises from adding the three differences $A_{1}-A_{2}+B_{1}-B_{2}+C_{1}-C_{2}$; this is equal to

$$
15 \mathrm{I}_{1}\left(\beta^{2}-\gamma^{2}\right)\left(\gamma^{2}-\alpha^{2}\right)\left(\alpha^{2}-\beta^{2}\right)=15 \mathrm{P}
$$

Also $A=\mathrm{P}_{6}{ }^{\prime}: \mathrm{B}=\mathrm{P}_{6}^{\prime \prime}: \mathrm{C}=\mathrm{P}_{6}{ }^{\prime \prime \prime}$, the accents having the meaning already explained. Thus we get

$$
\begin{aligned}
& \frac{2}{5} \mathrm{~A}_{1}=\mathrm{P}_{0}+\mathrm{P}_{6}{ }^{\prime}-3 \mathrm{~F}_{6}^{\prime \prime}-\mathrm{P}_{6}^{\prime \prime \prime}, \\
& \frac{2}{5} \mathrm{~A}_{2}=-\mathrm{P}_{0}-3 \mathrm{P}_{6}{ }^{\prime}+\mathrm{P}_{6}^{\prime \prime}-\mathrm{P}_{6}^{\prime \prime \prime}, \\
& \frac{2}{5} \mathrm{~B}_{1}=\mathrm{P}_{0}-\mathrm{P}_{6}{ }^{\prime}+\mathrm{P}_{6}^{\prime \prime}-3 \mathrm{P}_{6}{ }^{\prime \prime \prime}, \\
& \frac{2}{5} \mathrm{~B}_{2}=-\mathrm{P}_{0}-\mathrm{P}_{6}{ }^{\prime}-3 \mathrm{P}_{6}^{\prime \prime}+\mathrm{P}_{6}{ }^{\prime \prime \prime}, \\
& \frac{2}{5} \mathrm{C}_{1}=\mathrm{P}_{0}-3 \mathrm{P}_{6}^{\prime}-\mathrm{P}_{6}^{\prime \prime}+\mathrm{P}_{6}{ }^{\prime \prime \prime}, \\
& \frac{2}{5} \mathrm{C}_{2}=-\mathrm{P}_{0}+\mathrm{P}_{6}^{\prime}-\mathrm{P}_{6}^{\prime \prime}-3 \mathrm{P}_{6}^{\prime \prime \prime} .
\end{aligned}
$$

These have to be substituted in $Q_{6}$, with the following valnes for the integrals :-

$$
\begin{gathered}
\int x^{6} d m=\frac{1.3 .5}{5.7 .9} \mathrm{M} a^{6}: \int x^{2} y^{4} d m=\frac{1.3}{5.7 .9} \mathrm{M} a^{2} b^{4}: \\
\int x^{2} y^{2} z^{2} d m=\frac{\mathrm{M}}{5.7 .9} a^{2} b^{2} c^{2} .
\end{gathered}
$$

The result is

$$
\begin{array}{r}
\int \mathrm{Q}_{6} d m=\frac{1.3}{7.9} \frac{\mathrm{M}}{2}\left\{\mathrm{P}_{6}^{\prime} e_{2}^{2} e_{3}^{2}\left(e_{2}^{2}-e_{9}^{2}\right)+\mathrm{P}_{6}^{\prime \prime} e_{3}^{2} e_{1}^{2}\left(e_{3}^{2}-e_{1}^{2}\right)\right. \\
\left.+\mathrm{P}_{6}^{\prime \prime \prime} e_{1}^{2} e_{2}^{2}\left(e_{1}^{2}-e_{2}^{2}\right)+\mathrm{P} e_{1}^{2} e_{2}^{2} e_{3}^{2}\right\} .
\end{array}
$$

The sequence of the terms (2), (4), (6), which complete the series (1) as far as written down, is very remarkable, and suggests the idea that possibly an expression might be obtained for the general term. When the ellipsoid is one of revolution, so that $c=b$, and $e^{2}=c^{2}-a^{2}$,

$$
\mathrm{V}=\frac{\mathrm{M}}{r}\left\{1-\frac{3 \mathrm{P}_{2}^{\prime}}{3.5} \cdot \frac{e^{2}}{r^{2}}+\frac{3 \mathrm{P}_{4}^{\prime}}{5.7} \cdot \frac{e^{4}}{r^{4}}-\frac{3 \mathrm{P}_{6}^{\prime}}{7.9} \cdot \frac{e^{6}}{r^{6}}+\ldots\right\}
$$

